\title{
Exposed thoracic aortic endovascular stent graft
}

\author{
Tuan T. Lam, MD
}

\begin{abstract}
A 59-year-old man was admitted for unexplained anemia requiring multiple transfusions. His medical history was significant for traumatic aortic rupture and thoracolumbar spinal injury after a motor vehicle accident in 2012. The aortic injury was treated with an endovascular stent graft at an outside facility. Thoracic computed tomography showed a type I endoleak of the thoracic stent graft with a large pseudoaneurysm extending superiorly to the level of the left atrium, inferiorly to the level of the adrenal glands, posteriorly into the retroperitoneum of the abdomen, and laterally into the left side of the chest. An aortogram showed a large proximal type I endoleak and a smaller distal type I endoleak. Both the proximal and distal endoleaks were successfully treated with additional stent grafts, with coverage of the descending thoracic aorta from distal to the left subclavian artery to above the celiac artery.

Redo left thoracotomy was performed 1 week later to evacuate a large hemothorax and an empyema from pneumonia. The exposed thoracic aortic endovascular stent graft was seen after the hemothorax was evacuated and partial decortication performed (Figure 1). Most likely, the descending thoracic aorta had ruptured, resulting in acute anemia and the large left hemothorax. However, the aortic rupture was contained within the left thoracic cavity owing to the dense adhesions formed from the 2
\end{abstract}

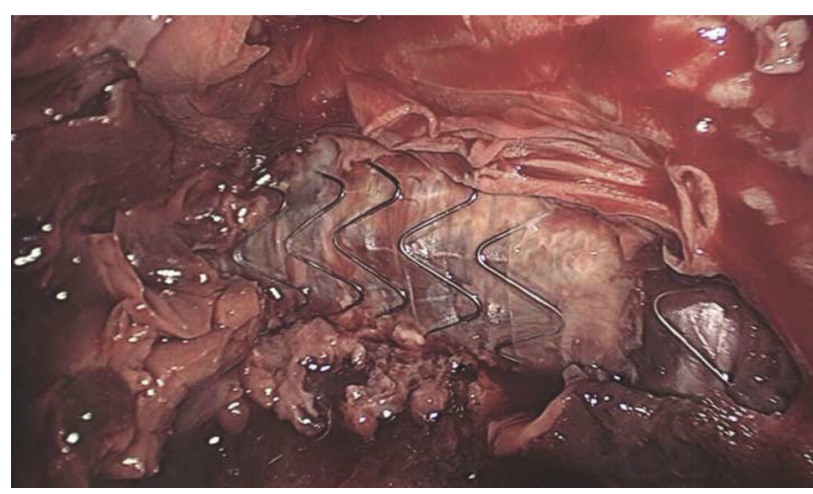

FIGURE 1. Exposed thoracic aortic stent graft after partial decortication and evacuation of the hemathorax of the left chest.

previous left thoracotomy operations and the recent empyema. The additional stent grafts implanted to treat the proximal and distal endoleaks effectively sealed the aortic rupture.

After evacuation of the hemothorax and empyema, the left lung remained trapped and would not expand to cover the exposed aortic stent graft. Clagett open window thoracostomy was performed to facilitate vacuum-assisted wound closure. At the first dressing change 3 days later, the aortic stent graft was already less exposed (Figure 2).
From the Orange Coast Memorial Medical Center, Fountain Valley, Calif. Disclosures: Author has nothing to disclose with regard to commercial support.

Received for publication Nov 10, 2013; accepted for publication Nov 22, 2013; available ahead of print Jan 10, 2014.

Address for reprints: Tuan T. Lam, MD, Orange Coast Memorial Medical Center, 2865 Atlantic Ave, Suite 205, Long Beach, CA 90806 (E-mail: tlammd@yahoo. com).

J Thorac Cardiovasc Surg 2014; 148:348

$0022-5223 / \$ 36.00$

Copyright (C) 2014 by The American Association for Thoracic Surgery

http://dx.doi.org/10.1016/j.jtcvs.2013.11.037

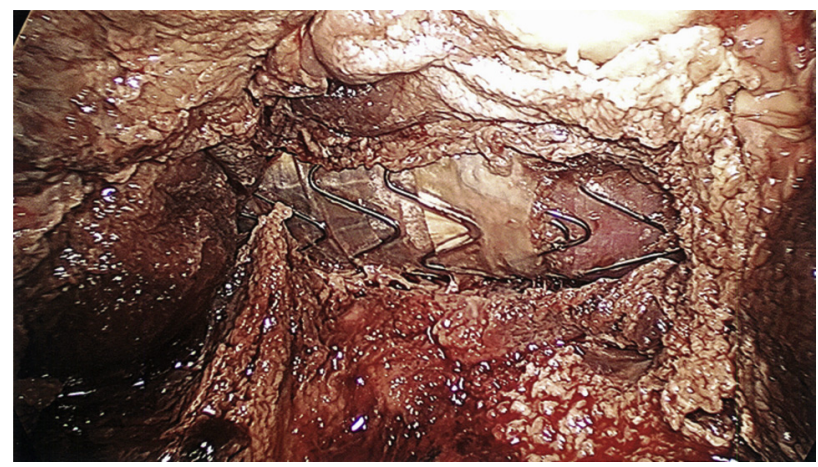

FIGURE 2. Less exposed thoracic aortic stent graft at the first dressing change on postoperative day 3 . 